\title{
Performance, Emission and Combustion Characteristics of Dual Fuel (DF) Engine Fuelled with Hydrogen Induction and Injection of Honne and Honge Methyl Esters
}

\author{
Rajshekhar S. Hosmath, Nagaraj R. Banapurmath, Mallikarjuna Bhovi, \\ Sanjeevkumar V. Khandal, Ajitkumar P. Madival, Shashikumar S. Dhannur, \\ Varunkumar Gundalli \\ Department of Mechanical Engineering, B. V. B. College of Engineering and Technology, Hubballi, India \\ Email: $\mathrm{nr}$ banapurmath@rediffmail.com
}

Received 17 April 2015; accepted 17 August 2015; published 20 August 2015

Copyright (C) 2015 by authors and Scientific Research Publishing Inc.

This work is licensed under the Creative Commons Attribution International License (CC BY).

http://creativecommons.org/licenses/by/4.0/

(c) (i) Open Access

\begin{abstract}
Renewable fuels like hydrogen and biodiesels can very well suit to diesel engine applications as they address problems of energy scarcity, foreign exchange savings and emission norms. Production of hydrogen and biodiesel to industrial scale with low cost techniques can pave way for their efficient use in engine applications. In view of this, an attempt has been made to operate a modified diesel engine on these high potential renewable fuel combinations. An experimental study was carried out to evaluate the performance, combustion and emission characteristics of diesel engine operated in dual fuel (DF) mode fuelled with esters of honne (EHNO), honge (EHO) oils and hydrogen induction. The study revealed that the brake thermal efficiency increased up to $20 \%$ hydrogen energy ratio (HER) and then it decreased. The emissions such as hydrocarbon (HC), Carbon monoxide (CO) and smoke decreased with HER while oxides of nitrogen $\left(\mathrm{NO}_{\mathrm{x}}\right)$ increased. The combustion parameters like peak pressure, ignition delay and heat release rate (HRR) increased with HER.
\end{abstract}

\section{Keywords}

Hydrogen, Carburetion, Ester of Honne Oil (EHNO), Ester of Honge Oil (EHO), Hydrogen Energy Ratio (HER)

How to cite this paper: Hosmath, R.S., Banapurmath, N.R., Bhovi, M., Khandal, S.V., Madival, A.P., Dhannur, S.S. and Gundalli, V. (2015) Performance, Emission and Combustion Characteristics of Dual Fuel (DF) Engine Fuelled with Hydrogen Induction and Injection of Honne and Honge Methyl Esters. Energy and Power Engineering, 7, 384-395.

http://dx.doi.org/10.4236/epe.2015.79036 


\section{Introduction}

Compression ignition engines are well known prime movers due to their higher BTE, as they are nowadays integral part of human life. They have higher exhaust emissions in the form of $\mathrm{NO}_{\mathrm{x}}$ and particulate matter (PM) and the scarcity of energy sources available makes them to operate on alternative and renewable fuel resources. There is urgent need for fuel alternatives which can replace diesel. Higher fuel economy and lower emissions are the expectations from these fuels. Biodiesels and hydrogen together enhance sustainability of the diesel driven economy and also hydrogen emits only water, lower $\mathrm{CO}$ and $\mathrm{HC}$ emissions. However, small traces of emissions in the exhaust are due to incomplete combustion of biodiesel and lubricating oil. Wider ignition limits and high burning velocity of hydrogen increase the BTE provided. The formatter will need to create these components, incorporating the applicable criteria that follow and can become energy carrier of the future. DF engine has major advantage of fuel flexibility that the engine can run in DF mode whenever gaseous fuel is available without much modification [1]. The maximum diesel substitution with biogas that was obtained about $49 \%$ in a single cylinder indirect injection diesel engine at rated load of $7.73 \mathrm{~kW}$ and speed of $1800 \mathrm{rpm}$ [2]. Some investigators used natural gas, producer gas, Liquefied Petroleum Gas LPG and $\mathrm{H}_{2}$ as fuels other than biogas in diesel engines. $\mathrm{NO}_{\mathrm{x}}$ emission decreased drastically by the utilization of natural gas as main fuel and diesel as pilot fuel in DF engine operation [3] $\mathrm{H}_{2}$ as an inducted fuel into the intake manifold fitted on the engine along with diesel as injected fuel into the cylinder in DF mode resulted in an increased BTE, reduction in $\mathrm{HC}, \mathrm{CO}_{2} \mathrm{CO}_{2}$ emissions and volumetric efficiency [4]. $\mathrm{NO}_{\mathrm{x}}$ emission increased and smoke decreased substantially with the addition of $\mathrm{H}_{2}$ into the diesel engine [5]. Higher amounts of $\mathrm{H}_{2}$ cannot be utilized in DF engines due to knocking problem of the engine. When water was inducted into the intake manifold along with $\mathrm{H}_{2}$ knock limited power output increased because it acted as the internal coolant which decreased the unburned mixture temperature [6]. Experimental work on a port injected $\mathrm{H}_{2}$ DF engine with varying water injection timings from 200 BTDC to 200 ATDC in steps of 100 crank Angle (CA) for two different injection durations of 200 and 400 CA revealed that better performance was due to increased indicated work and indicated thermal efficiency with the water injection timing of 200 ATDC and duration of 200 CA [7]. The performance and combustion characteristic of CI engine fueled with $\mathrm{H}_{2}$ under simulated DI diesel engine conditions was investigated [8]. The study focused on numerical analysis of neat diesel combustion mode and $\mathrm{H}_{2}$ enriched diesel combustion in a CI engine. The parameters varied in this simulation include $\mathrm{H}_{2}$ /diesel blend fuel ratio, engine speed, and air/fuel ratio. The results showed that using $\mathrm{H}_{2}$ as an extra fuel along with diesel in the CI engine resulted in improved engine performance and reduced emissions when compared with CI mode of engine operation. The combustion process approaches constant volume and a small amount of $\mathrm{H}_{2}$ when added to a diesel engine shorten the diesel ignition delay and decreased the pressure rise rate and provides better conditions for smooth operation of the engine. Comparative results were given for various $\mathrm{H}_{2}$ /diesel ratio, engine speeds and loads for neat diesel and DF operation, revealing the effect of DF combustion on engine performance and exhaust emissions. Hydrogen enriched engine operation produced the same brake power and higher BTE than CI engines [9]. With a lesser pilot quantity of diesel, hydrogen-enriched engines give higher BTE with smoother combustion than a CI engine. Increasing hydrogen flow rate beyond a certain quantity resulted in knocking; at the highest diesel flow rate, BTE was found to be the same as that of CI engines. BTE obtained by intake port injection method was higher than in-cylinder injection for all equivalence ratios used [10]. Hydrogen combustion provides higher cooling loss to the cylinder wall than fossil fuel combustion because of its higher burning velocity and very less quenching distance [11]. Highest BTE of 30\% was achieved at a compression ratio of 24.5 when hydrogen was used in the DF mode with diesel [12]. In dual injection, the stability and maximum power could be obtained by direct injection of hydrogen and the maximum BTE could be obtained by the external mixture formation in hydrogen fuelled engine [13]. The hydrogen intake port injection operated engine showed improved performance by $9 \%$ compared with normal CI operation [14]. The BTE of $\mathrm{H}_{2}$-diesel DF engine depends upon the amount of $\mathrm{H}_{2}$ added that is the larger the amount of $\mathrm{H}_{2}$ added, the higher the value of BTE obtained [15]. In $\mathrm{H}_{2}$-diesel DF engine operation $90 \%$ enriched $\mathrm{H}_{2}$ gave higher BTE than $30 \%$ at $70 \%$ load and knocking problem encountered at higher load. Also drop in BTE was observed with $\mathrm{H}_{2}$ less than or equal to 5\%. The researchers [14]-[16] studied the variation of $\mathrm{H}_{2}$-diesel quantity for constant diesel supply at different loads to improve the brake power and BTE and they found that increasing in the $\mathrm{H}_{2}$ flow rate in inlet manifold resulted reduction in the air flow to the engine cylinder by which volumetric efficiency and consequently the BTE of the engine reduced.

The objective of the present work is to study the performance, emissions and combustion characteristics of 
DF by varying the hydrogen energy ratio maintaining constant speed of 1500 RPM at $40 \%, 60 \%$ and $80 \%$ loads. The engine was run on DF mode using different combinations of $\mathrm{H}_{2}$-diesel and $\mathrm{H}_{2}$-biodiesels.

\section{Experimental Work}

\subsection{Experimental Methodology}

The engine used for the investigation is four-stroke water cooled, single cylinder, DI CI engine developing a rated power $5.2 \mathrm{~kW}$ at rated constant speed of $1500 \mathrm{rpm}$. The properties of the fuels used are shown in Table 1. The properties of hydrogen are given in Table 2. The specifications of the engine are given in Table 3 . The engine is coupled to an eddy current dynamometer with resistance loading. The engine head is mounted with a piezo sensor for pressure-crank angle acquisition. At each load 100 cycles of pressure-crank angle history can be stored in high storage computer. Liquid Fuel consumption was measured on volume basis. Exhaust gas analyzer was used to measure $\mathrm{CO}, \mathrm{CO}_{2}, \mathrm{HC}, \mathrm{NO}_{\mathrm{x}}, \mathrm{O}_{2}$ and its details are given in Table 4 while Smoke was measured using Hartridge Smoke meter and its details are given in Table 5. Figure 1 shows the experimental set up used in the study.

Table 1. Properties of liquid fuels used.

\begin{tabular}{ccccc}
\hline Sl. No. & Properties & Diesel & EHNO & EHO \\
\hline 1 & Viscosity $@ 40^{\circ} \mathrm{C}(\mathrm{cst})$ & $2-5$ & 4.5 & 5.6 \\
2 & Flash point ${ }^{\circ} \mathrm{C}$ & 75 & 187.5 & 163 \\
3 & Calorific Value $(\mathrm{kJ} / \mathrm{kg})$ & 43,000 & 39,798 & 36,010 \\
4 & Density $\mathrm{kg} / \mathrm{m}^{3}$ & 840 & 880 & 890 \\
5 & Cetane Number & $45-55$ & 40 & $40-42$ \\
6 & Oxidation stability & Ligh & Now & Low \\
7 & Sulphur Content & High & No \\
\hline
\end{tabular}

Table 2. Properties of hydrogen.

\begin{tabular}{|c|c|c|}
\hline Sl. No. & Properties & Hydrogen \\
\hline 1 & Chemical Formula & $\mathrm{H}_{2}$ \\
\hline 2 & Density at $1 \mathrm{~atm}$ and $300 \mathrm{~K}\left(\mathrm{~kg} / \mathrm{m}^{3}\right)$ & 0.08 \\
\hline 3 & Calorific value (MJ/kg) & 119.7 \\
\hline 4 & Cetane Number & - \\
\hline 5 & Kinematic viscosity at $300 \mathrm{~K}\left(\mathrm{~mm}^{2} / \mathrm{s}\right)$ & 110 \\
\hline 6 & Thermal conductivity at $300 \mathrm{~K}$ (W/mK) & 182 \\
\hline 7 & Diffusion coefficient into air at NTP $\left(\mathrm{cm}^{2} / \mathrm{s}\right)$ & 0.61 \\
\hline 8 & Boiling point $(\mathrm{K})$ & 20.27 \\
\hline 9 & Molecular weight (g/mole) & 2.015 \\
\hline 10 & Combustion energy per kg of stoich. mixture (MJ) & 3.37 \\
\hline 11 & Flammability limits (\% by volume) & $4-75$ \\
\hline 12 & Flammability limits (Equivalence ratio) & $0.1-6.9$ \\
\hline 13 & Laminar flame speed at NTP (m/s) & 1.9 \\
\hline 14 & Max deflagration speed (m/sec) & 3.5 \\
\hline 15 & Minimum ignition energy (mJ) & 0.02 \\
\hline 16 & Adiabatic flame temperature (K) & 2318 \\
\hline 17 & Auto ignition temperature (K) & 858 \\
\hline
\end{tabular}


Table 3. Engine specification.

\begin{tabular}{|c|c|c|}
\hline Sl. No. & Parameter & Specifications \\
\hline 1 & Machine supplier & Apex Innovations Pvt Ltd. Sangli, Maharashtra, India \\
\hline 2 & Type & TV1 (Kirloskar make) \\
\hline 3 & Software used & Engine soft \\
\hline 4 & Nozzle opening pressure & 200 to 225 bar \\
\hline 5 & Governor type & Mechanical centrifugal type \\
\hline 6 & No of cylinders & Single cylinder \\
\hline 7 & No of strokes & Four stroke \\
\hline 8 & Fuel & H. S. Diesel \\
\hline 9 & Rated power & 5.2 KW (7 HP) @1500 RPM \\
\hline 10 & Cylinder diameter (Bore) & $0.0875 \mathrm{mtr}$ \\
\hline 11 & Stroke length & $0.11 \mathrm{mtr}$ \\
\hline 12 & Compression ratio & 17.5:1 \\
\hline \multicolumn{3}{|c|}{ Air Measurement Manometer: } \\
\hline 13 & Make & MX 201 \\
\hline 14 & Type & U-Type \\
\hline 15 & Range & $100-0-100 \mathrm{~mm}$ \\
\hline \multicolumn{3}{|c|}{ Eddy current dynamometer: } \\
\hline 16 & Model & AG-10 \\
\hline 17 & Type & Eddy current \\
\hline 18 & Maximum & $7.5 \mathrm{KW}$ at 1500 to $3000 \mathrm{RPM}$ \\
\hline 19 & Flow & Water must flow through Dynamometer during the use \\
\hline 20 & Dynamometer arm length & $0.180 \mathrm{mtr}$ \\
\hline 21 & Fuel measuring unit-Range & 0 to $50 \mathrm{ml}$ \\
\hline
\end{tabular}

\section{Table 4. Specifications of exhaust gas analyzer.}

\section{Type}

Object of measurement

Range of measurement

Resolution

Warm up time

Speed of response time

Sampling

Power source

Weight
DELTA $1600 S$

Carbon monoxide (CO), Carbon Dioxide $\left(\mathrm{CO}_{2}\right)$ and Hydrocarbons (HC)

$\mathrm{HC}=0$ to $20,000 \mathrm{ppm}$ as $\mathrm{C}_{3} \mathrm{H}_{8}$ (Propane)

$\mathrm{CO}=0 \%$ to $10 \%$

$\mathrm{CO}_{2}=0 \%$ to $16 \%$

$\mathrm{O}_{2}=0 \%$ to $21 \% \mathrm{NO}_{\mathrm{x}}=0$ to $5000 \mathrm{ppm}$ (as Nitric Oxide)

$\mathrm{HC}= \pm 30 \mathrm{ppm} \mathrm{HC}$

$\mathrm{CO}= \pm 0.2 \% \mathrm{CO}$

$\mathrm{CO}_{2}= \pm 1 \% \mathrm{CO}_{2}$

$\mathrm{O}_{2}= \pm 0.2 \% \mathrm{O}_{2}$

$\mathrm{NO}_{\mathrm{x}}= \pm 10 \mathrm{ppm} \mathrm{NO}$

$\mathrm{HC}=1 \mathrm{ppm}$

$\mathrm{CO}=0.01 \% \mathrm{Vol}$

$\mathrm{CO}_{2}=0.1 \% \mathrm{Vol}$

$\mathrm{O}_{2}=0.01 \% \mathrm{Vol}$.

$\mathrm{NO}_{\mathrm{x}}=1 \mathrm{ppm}$

$10 \mathrm{~min}$. (self-controlled) at $200 \mathrm{C}$

Within 15 sec. for $90 \%$ response

Directly sampled from tail pipe

100 to $240 \mathrm{~V} \mathrm{AC} / 50 \mathrm{~Hz}$

$800 \mathrm{gm}$.

Size

$100 \mathrm{~mm} \times 210 \mathrm{~mm} \times 50 \mathrm{~mm}$ 
Table 5. Specifications of smoke meter.

\begin{tabular}{cc}
\hline Type & HARTRIDGE SMOKEMETER-4 \\
\hline Object of measurement & Smoke \\
Measuring range opacity & $0 \%-100 \%$ \\
Accuracy & $\pm 2 \%$ relative \\
Resolution & $0.1 \%$ \\
Smoke length & $0.43 \mathrm{~m}$ \\
Ambient Temperature Range & $-50 \mathrm{C}$ to $+450 \mathrm{C}$ \\
Warm up time & 10 min. (self-controlled) at $200 \mathrm{C}$ \\
Speed of response time & Within 15 sec. for $90 \%$ response \\
Sampling & Directly sampled from tail pipe \\
Power Supply & 100 to $240 \mathrm{~V}$ AC/50 HZ \\
Size & $10-16$ V DC 15 amps \\
& $100 \mathrm{~mm} \times 210 \mathrm{~mm} \times 50 \mathrm{~mm}$. \\
\hline
\end{tabular}
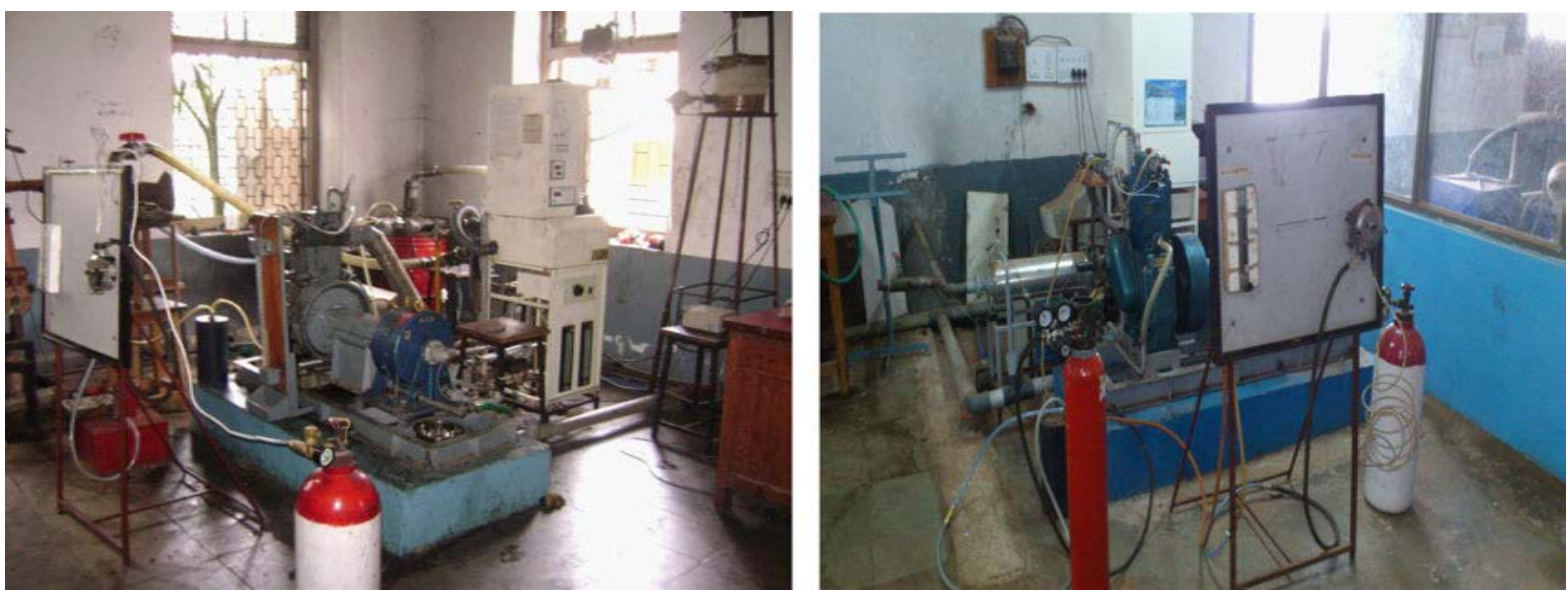

Figure 1. Experimental set up details.

\subsection{Gas Supply to Engine}

Hydrogen gas at 150 bar stored in high pressure cylinder is supplied to the engine at an out let pressure of 1.5 bars using dual pressure regulator mounted on the hydrogen cylinder. Hydrogen is first passed through a flow control valve which supplies it at rate required and then it is passed through the gas flow meter, the unit of flow being liters per minute (LPM) and $\mathrm{m}^{3} / \mathrm{s}$. From the flow meter Hydrogen enters flame arresters which suppress possible fire hazards in the system. The flame arrestors works on principal that flame gets quenched if sufficient heat is removed from the gas by arrestors which act as non-return valve. Finally hydrogen is allowed to pass through flame trap, which suppress the flash back if any in to the intake manifold. Two types of flame traps used during experimentation are wet type and dry type, wet flashback arrestor's work by bubbling the gas through a nonflammable and ideally on gas-absorbing liquids which are water. Hydrogen gas from high pressure cylinder after passing through the flame trap is inducted by means of carburation's technique using gas carburetor. The measurement range and its accuracy for different parameters are given in Table 4. All experimental measurements, irrespective of the type of instrument used, possess some uncertainty. The engine is always started with diesel/biodiesel and after starting the engine the diesel and biodiesel flow is reduced by adjusting the fuel pump rack simultaneously and hydrogen is supplied into the intake manifold through an in-house designed gas carburetor at the rated speed of $1500 \mathrm{rpm}$. The load is then increased from $40 \%$ to $80 \%$ in steps of $20 \%$ and the hydrogen flow increased maintaining constant speed of $1500 \mathrm{rpm}$. 


\section{Results and Discussion}

The carburetion technique was used to obtain hydrogen gas-air mixture and diesel, biodiesel in-turn were used as ignition source. The performance, combustion and emission characteristics of DF engine operation were compared for diesel and biodiesel combination with hydrogen source being common. Hydrogen energy ratio (HER) is defined as the ratio of energy contribution by hydrogen ( $\mathrm{EC}_{\text {Hydrogen }}$ ) to the energy contribution by both hydrogen and liquid fuel $\left(\mathrm{EC}_{\mathrm{Hydrogen}}+\mathrm{EC}_{\mathrm{LF}}\right)$.

$$
\text { Hydrogen Energy ratio }=\frac{\left(\mathrm{EC}_{\text {Hydrogen }}\right)}{\left(\mathrm{EC}_{\text {Hydrogen }}+\mathrm{EC}_{\mathrm{LF}}\right)}
$$

\subsection{Brake Thermal Efficiency}

The Figure 2 depicts the variation of BTE with HER for $40 \%, 60 \%$ and $80 \%$ loads respectively. The BTE increased with increase in HER and load up to $20 \%$ then it decreased. The higher flame velocity of hydrogen improved mixing of liquid fuels injected with air and enhanced combustion rate that led to higher BTE and similar results were reported in the literature [16]. This could be due to a loss of fuel escaping through intake manifold as flow of hydrogen is continuous during the engine operation. Hydrogen being common, the BTE with biodiesel was inferior compared to diesel operation due to its higher viscosity, lower volatility and lower calorific value. In addition to this the partially replaced hydrogen through manifold induction further lowers BTE due to its lower density. This can be further improved by injecting hydrogen in manifold injector using a low pressure gas injector (5 bar). Also higher heat loss due to higher wall heat flux of hydrogen combustion is another reason for lower BTE (Owston et al. 2007). Advanced combustion phasing due to hydrogen addition lowers BTE (Liew C 2010). The engine noise was observed to be more while the engine was running in dual fuel mode. The noise level increased with increase in hydrogen admission for all load conditions. This was mainly due to rapid combustion of methyl esters of EHO and EHNO in the presence of hydrogen.

\subsection{Hydrocarbon Emission}

The variation of HC emission with HER for different loading conditions is shown in Figure 3. HC emission was

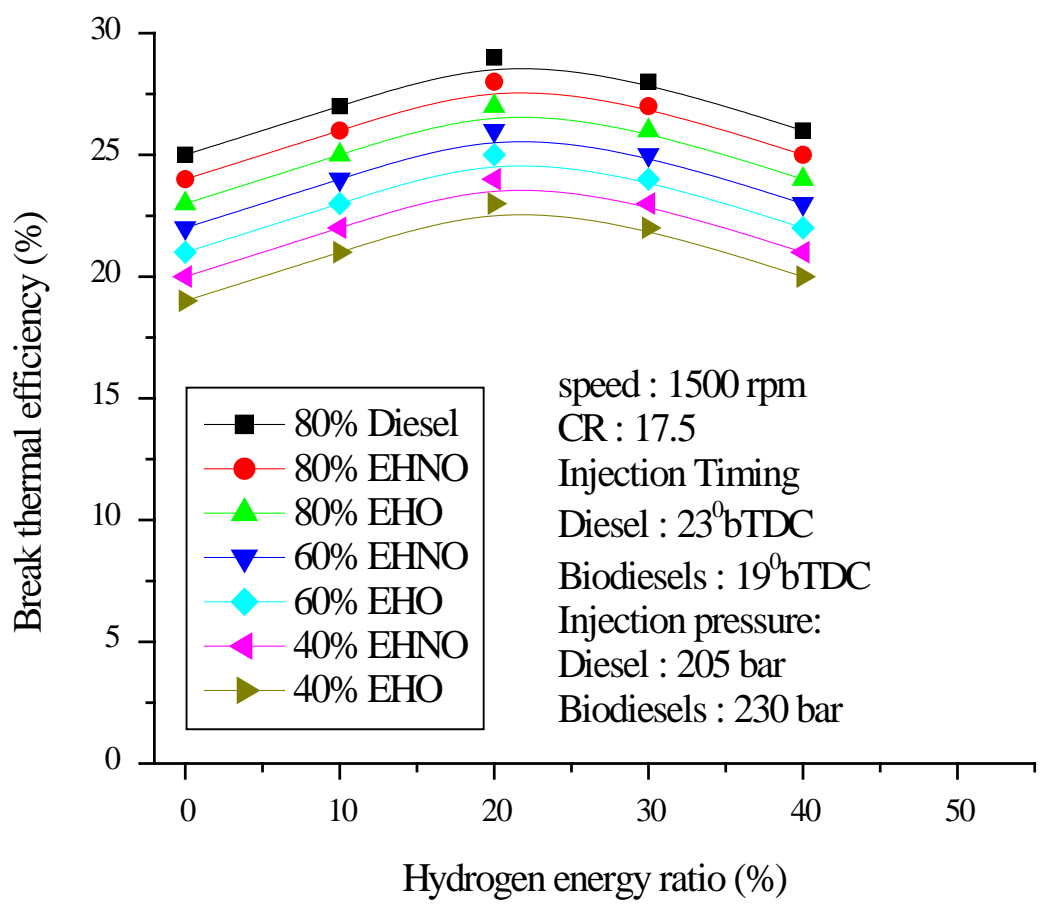

Figure 2. Variation of BTE with Hydrogen energy ratio. 


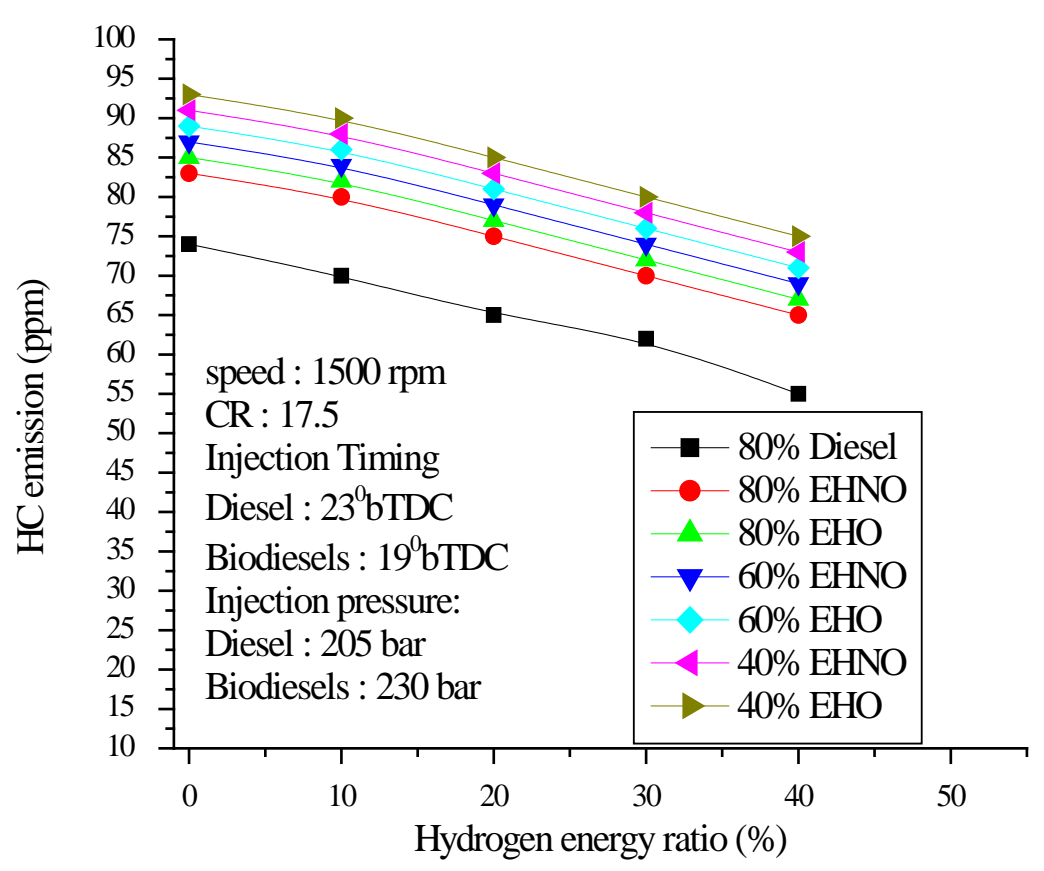

Figure 3. Variation of HC with Hydrogen energy ratio.

always lower with diesel mode of DF engine operation compared to its counterpart biodiesel. HC emission increases with increased loading conditions as more liquid fuel is injected inside the engine cylinder. As the flow rate of hydrogen increases the HC emission decreases which could be due to absence of carbon atoms in structure of hydrogen fuel. HC emission in the exhaust was due to lubricating oil combustion and partial combustion of biodiesel. However there was no significant decrease in HC emission due to increase in hydrogen flow rate at higher loads and similar results were revealed by Tarkan Sandalci 2014.

Higher HC emissions were observed for the injected biodiesels compared to diesel with hydrogen induction. The lower brake thermal efficiency coupled with wall wetting in the case of injected biodiesels could also be the reason for this observed trend of increased HC emission. Since hydrogen has no carbon, burning of hydrogen along with methyl esters leads to increased hydrocarbon level. Some HC emission is found because of carbon present in lubricating oil as well as biodiesels. And also because of high cylinder temperature the carbon particles, present in lubricating oil and main fuel, gets oxidized and gets converted into $\mathrm{CO}_{2}$.

\subsection{Carbon Monoxide Emission}

The variation of CO emission with HER is shown in Figure 4. CO emissions were lower for diesel DF engine operation compared to biodiesel with hydrogen induction common in the two cases. Increasing trend was found with increase in load for all dual fuel combinations. $\mathrm{CO}$ emission increases with increased loading conditions as more liquid fuel is injected inside the engine cylinder as shown in Figure As the flow rate of hydrogen increases the $\mathrm{CO}$ emission decreases which could be due to absence of carbon atoms in hydrogen fuel. Higher in cylinder pressure due to higher flame propagation speed of hydrogen fuel, complete combustion due to enhanced homogeneous mixture because of higher diffusivity of hydrogen and availability of more oxygen led to reduced CO emission (Gazhal O.H. 2013). The traces of CO emission in the exhaust could be due to lubricating oil combustion and also partial combustion of biodiesel. The variation of the carbon monoxide with hydrogen enrichment at selected loads is shown in the Figure. It is found that the carbon monoxide was decreased with increase in hydrogen addition. At all the loads induction of hydrogen lowers CO levels. The reason for lower CO emission is due to absence of carbon atoms in the hydrogen structure.

\subsection{Nitrogen Oxide Emission}

The variation of $\mathrm{NO}_{\mathrm{x}}$ emission with HER is shown in Figure 5 for different higher loads. Reaction time, oxygen 


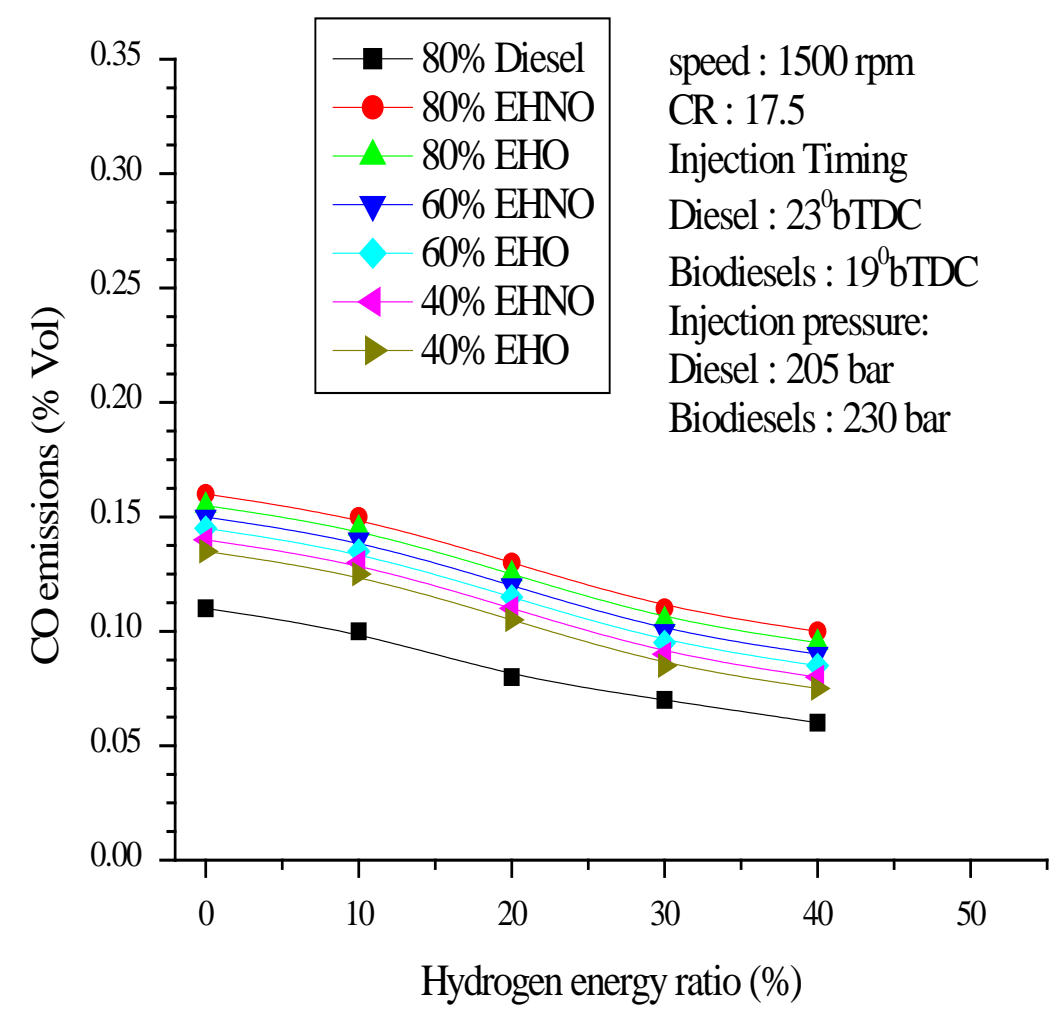

Figure 4. Variation of CO with Hydrogen energy ratio.

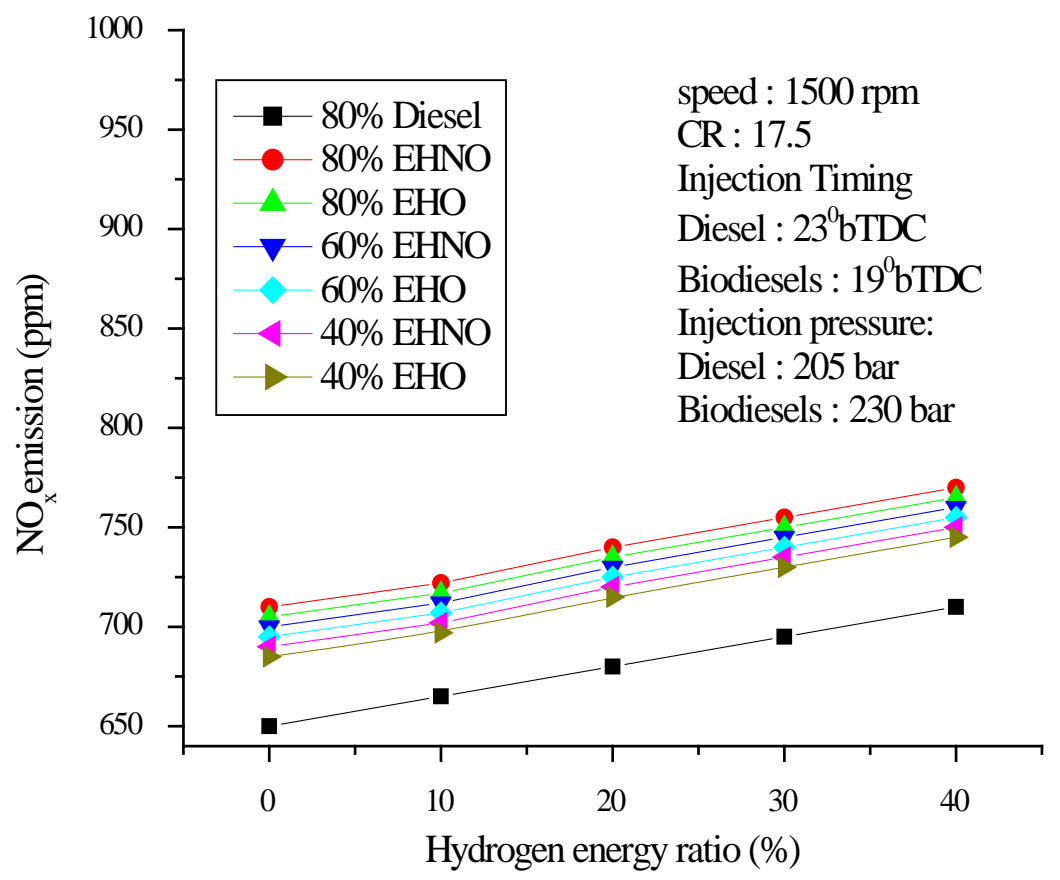

Figure 5. Variation of $\mathrm{NO}_{\mathrm{x}}$ with Hydrogen energy ratio.

concentration and in-cylinder temperature are the reasons for $\mathrm{NO}_{\mathrm{x}}$ formation (Kose $\mathrm{H}$. 2013). $\mathrm{NO}_{\mathrm{x}}$ emission was always higher in dual fuel mode of engine operation using diesel compared to its counterpart biodiesel. The reasons for this could be that hydrogen being a common fuel in both versions premixed heat release rate associated 
with biodiesel is comparatively lower. Increased $\mathrm{NO}_{\mathrm{x}}$ emission could be due to higher in-cylinder pressure and temperature and longer stay time of high temperature gases inside the cylinder due to complete combustion of mixture (Saravanan 2007, Liew C. 2010). NOx emission increases with increased loading conditions as more liquid fuel is injected for the same power to be developed inside the engine cylinder.

\subsection{Smoke Emission}

The variation of smoke emission with HER for different loading conditions is shown in Figure 6. Increase in smoke emission was observed with increased loads. Hydrogen being common smoke emission with diesel engine operation was lower compared to the two biodiesels of EHO and EHNO respectively. The higher viscosity and lower volatility of the biodiesels results into improper fuel air mixtures and hence higher smoke emissions due to incomplete combustion occurs. Smoke further decreases as the flow rate of hydrogen is increased. Complete combustion due to enhanced homogeneous mixture because of higher diffusivity of hydrogen and availability of more oxygen led to lower smoke emission and the trend were similar for both liquid fuels injected (Gazhal 2013, Szwaja 2009).

\subsection{Peak Pressure}

The variation of Peak pressure with HER is shown in Figure 7 for different loading conditions. Peak pressure was higher in diesel-hydrogen dual fuel mode of operation compared to biodiesel-hydrogen version. Hydrogen being common the higher premixed combustion observed with diesel could be responsible for the observed peak pressure variations. Peak pressure increased with increased HER and this could be due to high flame speed of hydrogen and become maximum with instantaneous combustion of hydrogen fuel (Saravanan 2007).

\subsection{Ignition Delay (ID) and Heat Release Rate (HRR)}

The variation of ID and HRR with HER is shown in Figure 8 and Figure 9. The ID increases with increase in HER for all the loads due to high flame speed advanced combustion phasing occurring with HER. ID increases with increasing loads due to increased amount of liquid fuels taking part in the combustion when injected inside

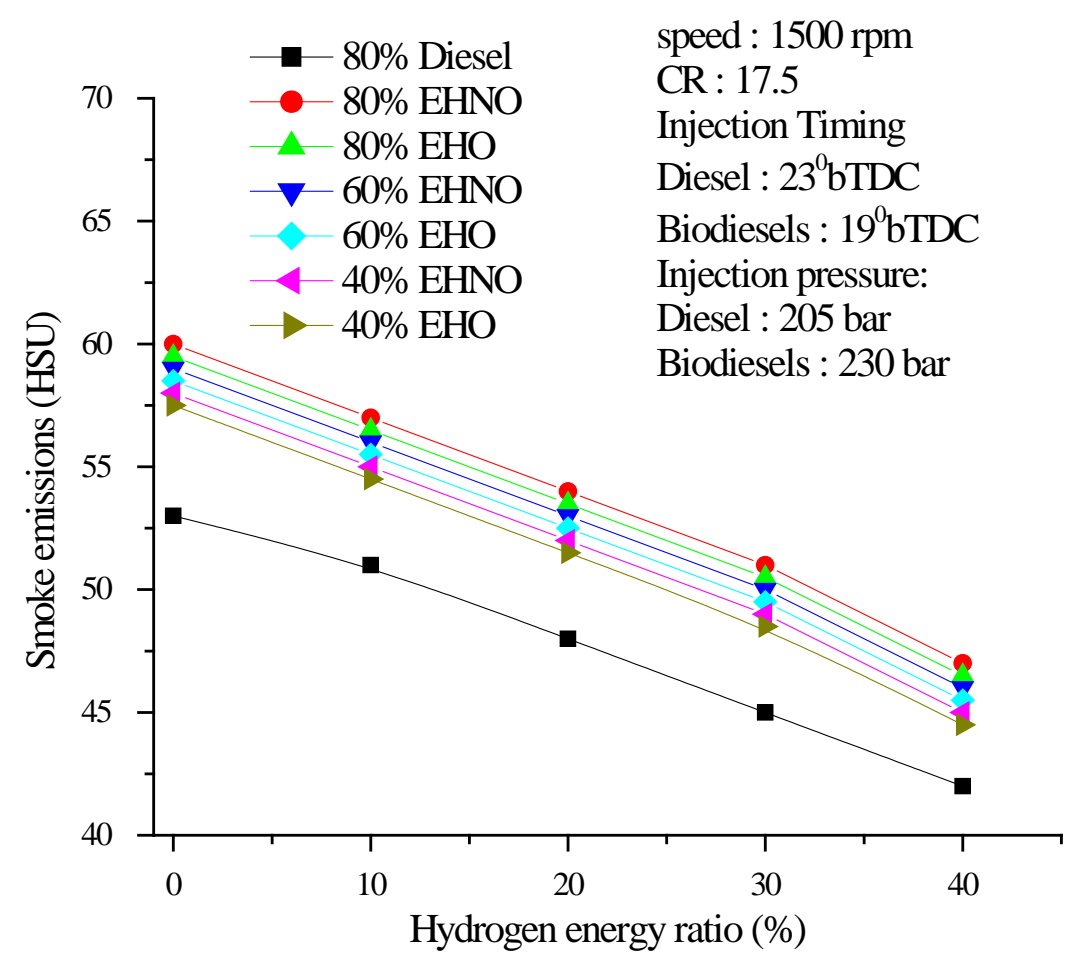

Figure 6. Variation of Smoke with Hydrogen energy ratio. 


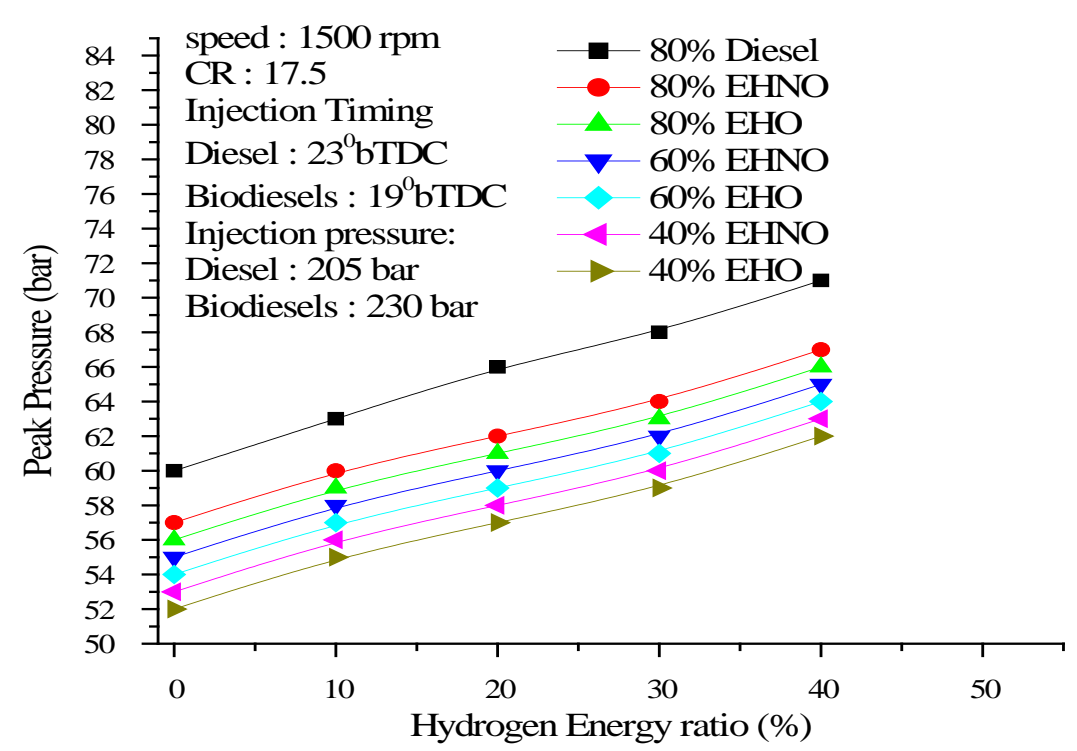

Figure 7. Variation of peak pressure with Hydrogen energy ratio.

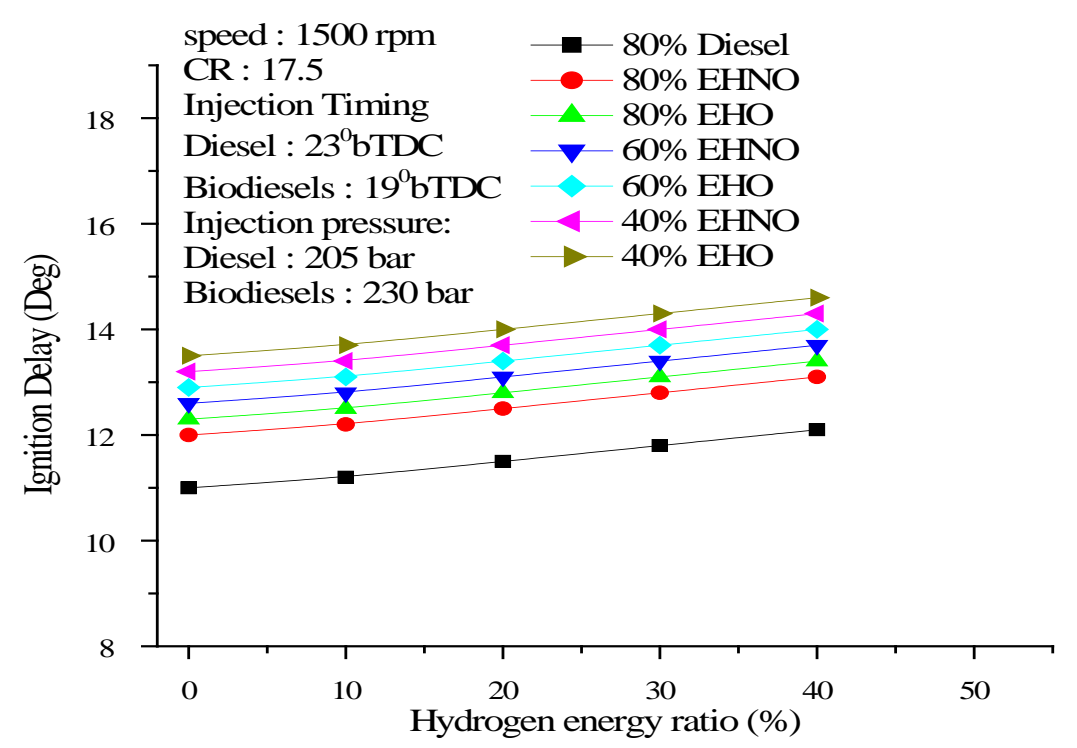

Figure 8. Variation of ID with Hydrogen energy ratio.

the combustion chamber. EHO and EHNO showed higher ID compared to diesel due their sluggish combustion associated with their higher viscosity and lower volatility as well.

HRR is higher with diesel-hydrogen dual fuel engine operation compared to biodiesel-hydrogen fuel combinations. Higher premixed combustion observed with diesel-hydrogen combination could also be responsible for this observed trend. HRR increased as the flow rate of hydrogen increased which could be due to higher energy content of hydrogen and high flame speed advanced combustion phasing. Increases in hydrogen flow rate have significant effect on premixed combustion than diffusion combustion. Similar results were found in the literature (Saravanan 2007).

\section{Conclusions}

From the exhaustive experimentation conducted on diesel and Biodiesel-hydrogen fuel combinations in a modified CI engine operated in DF mode, the following conclusions are drawn. 


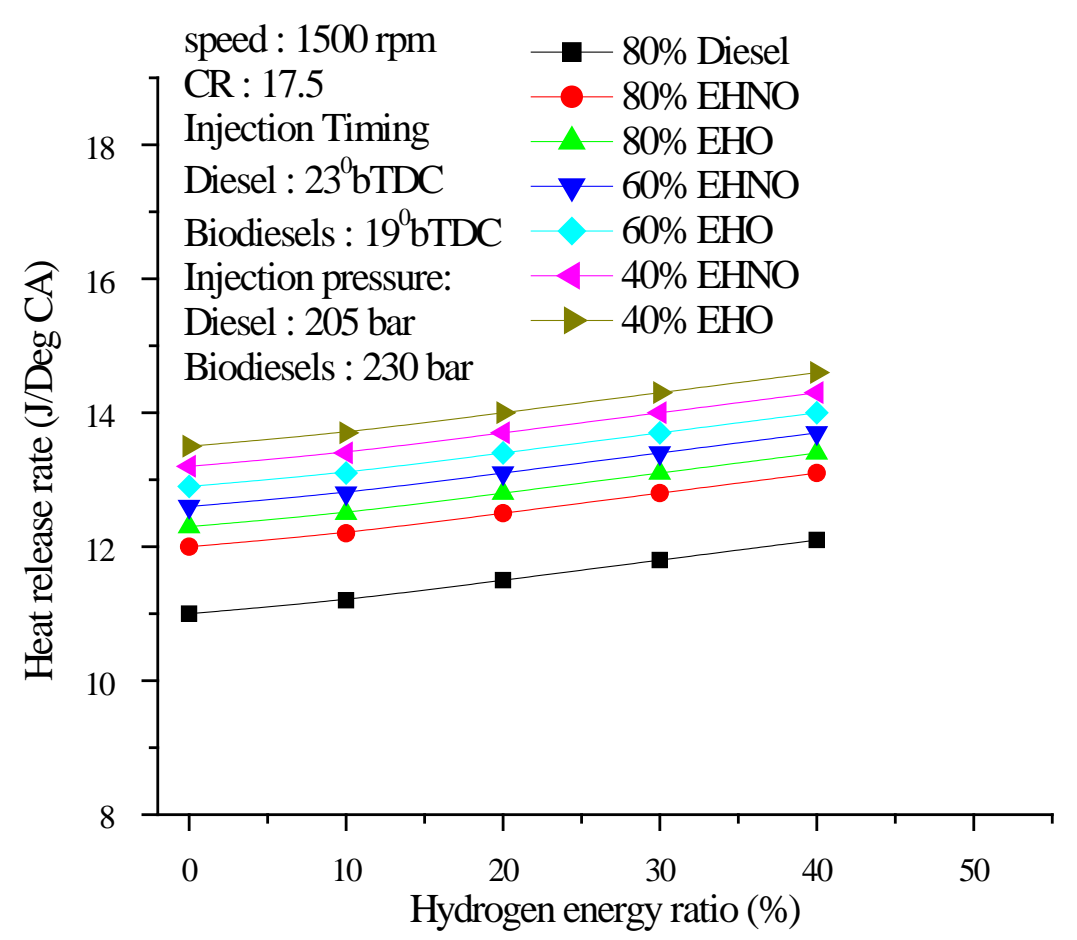

Figure 9. Variation of HRR with Hydrogen energy ratio.

1) The brake thermal efficiency increases with increased HER and this is observed till 20\% HER. At high rates of hydrogen induction into the intake manifold, combustion becomes uncontrolled and hence the brake thermal efficiency decreases.

2) The reduced performance of dual fuel engine is mainly associated with hydrogen induction which displaces the air quantity and hence volumetric efficiency suffers.

3) Due to enhanced combustion rates of hydrogen $\mathrm{NO}_{\mathrm{x}}$ is higher in case of hydrogen induction in the intake manifold.

4) The smoke level decreases for hydrogen induction in diesel dual fuel operation compared with biodiesel operation. The reduction in smoke is due to the absence of carbon in hydrogen structure.

5) The HC and CO emissions decrease for increased HER in both diesel and biodiesel-Hydrogen fuel combinations at all the loading conditions.

6) Combustion parameters like peak pressure, ID, HRR were determined using Pressure-Crank angle history acquisition considering 100 cycles. Peak pressure, ID and HRR increased with HER.

On the closure, it can be concluded that the hardware developed for hydrogen induction in diesel and biodiesel operated dual fuel operated successfully. Higher HER resulted into erratic engine operation and limiting the hydrogen induction. Manifold or port injection of hydrogen in such dual fuel engines could further improve the performance and emission characteristics using renewable fuel combination for total fossil fuel substitution besides ensuring sustained energy development.

\section{References}

[1] Babu, M.K.G. and Subramanian, K.A. (2013) Alternative Transportation Fuels: Utilisation in Combustion Engines. CRC Press, New York.

[2] Duc, P.M. and Wattanavichien, K. (2007) Study on Biogas Premixed Charge Diesel Dual-Fuelled Engine. Energy Convers Manage, 48, 2286-2308. http://dx.doi.org/10.1016/j.enconman.2007.03.020

[3] Ryu, K. (2013) Effects of Pilot Injection Pressure on the Combustion and Emissions Characteristics in a Diesel Engine Using Biodiesel_CNG Dual-Fuel. Energy Convers Manage, 76, 506-516. http://dx.doi.org/10.1016/j.enconman.2013.07.085

[4] Saravanan, N. (2009) An Experimental Investigation on Manifold-Injected Hydrogen as a Dual-Fuel for Diesel Engine 
System with Different Injection Duration. International Journal of Energy Research, 3, 1352-1366. http://dx.doi.org/10.1002/er.1550

[5] Varde, K.S. and Frame, G.A. (1983) Hydrogen Aspiration in a Direct Injection Type Diesel Engine-Its Effects on Smoke and other Engine Performance Parameters. International Journal of Hydrogen Energy, 8, 549-555.

[6] Prabhukumar, G.P., Swaminathan, S., Nagalingam, B. and Gopalakrishnan, K.V. (1987) Water Induction Studies in a Hydrogen-Diesel Dual-Fuel Engine. International Journal of Hydrogen Energy, 12, 177-186. http://dx.doi.org/10.1016/0360-3199(87)90151-0

[7] Adnan, R., Masjuki, H.H. and Mahlia, T.M.I. (2012) Performance and Emission Analysis of Hydrogen Fuelled Compression Ignition Engine with Variable Water Injection Timing. Energy, 43, 416-426. http://dx.doi.org/10.1016/j.energy.2012.03.073

[8] Ghazal, O.H. (2013) Performance and Combustion Characteristic of CI Engine Fueled with H2. International Journal of Hydrogen Energy, 38, 15469-15476.

[9] Haragopala Rao, B., Shrivastava, K.N. and Bhakta, H.N. (1983) Hydrogen for Dual Fuel Engine Operation. International Journal of Hydrogen Energy, 8, 381-384. http://dx.doi.org/10.1016/0360-3199(83)90054-X

[10] Yi, H.S., Min, K. and Kim, E.S. (2000) Optimized Mixture Formation for Hydrogen Fuelled Engines. International Journal of Hydrogen Energy, 25, 685-690. http://dx.doi.org/10.1016/S0360-3199(99)00082-8

[11] Shudo, T. and Suzuki, H. (2002) Applicability of Heat Transfer Equations to Hydrogen Combustion. JSAE Review, 23, 303-308. http://dx.doi.org/10.1016/S0389-4304(02)00193-5

[12] Masood, M., Ishrat, M.M. and Reddy, A.S. (2007) Computational Combustion and Emission Analysis of Hydrogen-Diesel Blends with Experimental Verification. International Journal of Hydrogen Energy, 32, 2539-2547. http://dx.doi.org/10.1016/j.ijhydene.2006.11.008

[13] Lee, J.T., Kim, Y.Y., Lee, C.W. and Caton, J.A. (2001) An Investigation of a Cause of Backfire and Its Control Due to Crevice Volumes in a Hydrogen Fueled Engine. Journal of Engineering for Gas Turbines and Power, 123, 204-210.

[14] Lee Jong, T., Kim, Y.Y. and Caton, J.A. (2002) The Development of a Dual Injection Hydrogen Fueled Engine with High Power and High Efficiency. Proceedings of the 2002 Fall Technical Conference of ASME-ICED, New Orleans, 8-11 September 2002, 323-333. http://dx.doi.org/10.1115/icef2002-514

[15] Gopal, G., Rao, P.S., Gopalakrishnan, K.V. and Murthy, B.S. (1982) Use of Hydrogen in Dual-Fuel Engines. International Journal of Hydrogen Energy, 7, 267-272. http://dx.doi.org/10.1016/0360-3199(82)90090-8

[16] Das, L.M. (2002) Hydrogen Engine Research and Development (R\&D) Programmes in Indian Institute of Technology (IIT), Delhi. International Journal of Hydrogen Energy, 27, 953-965. http://dx.doi.org/10.1016/S0360-3199(01)00178-1 